\title{
TRADICIÓN E INNOVACIÓN TEMÁTICA Y MÉTRICA EN LAS LATINAS O POESÍAS CASTELLANAS EN METRO LATINO DE ESTEBAN MANUEL DE VILLEGAS
}

\author{
María Ángeles Díez Coronado \\ Universidad de La Rioja ${ }^{1}$
}

\section{Resumen}

Esteban Manuel de Villegas, oriundo de Matute, La Rioja, se presenta en el panorama literario español del siglo XviI como una rara avis. Desde su más temprana juventud, cuando comienza su producción, se provee a sí mismo de un canon literario de corte clásico en cuanto a contenidos y estructura y moldea sus composiciones poéticas con unos criterios alejados de las tendencias del momento, pensando que con el resultado superará incluso a los ya consagrados autores del Siglo de Oro español. Una de sus apuestas más arriesgadas la materializa en el libro cuarto de la segunda parte de Las Eróticas o amatorias, obra que publica en 1618.

En el artículo que sigue se contextualiza la vida literaria del autor, se describe grosso modo su obra poética y se comentan desde el punto de vista del contenido y la métrica varias composiciones de su libro titulado Las latinas con la idea de mejorar el conocimiento de un autor que, aunque no logra eclipsar, a pesar de intentarlo desde la misma portada de su trabajo, a los autores que vertebran la literatura española del Siglo de Oro; sin embargo, sí que adopta unas acertadas decisiones sobre cuestiones métricas en un momento de asentamiento de criterios compositivos en verso.

Palabras clave: Tradición clásica, Esteban Manuel de Villegas, Siglo de Oro, métrica.

\section{TRADITION AND THEMATIC AND METRICAL INNOVATION IN LAS LATINAS O POESÍAS CASTELLANAS EN METRO LATINO BY ESTEBAN MANUEL DE VILLEGAS}

\begin{abstract}
Esteban Manuel de Villegas, born in Matute (La Rioja, Spain), is a rara avis in the Spanish literary panorama of the 17th century. From his earliest youth, when he begins

1 Este trabajo se ha llevado a cabo con una ayuda para estudios científicos de temática riojana subvencionada por el Instituto de Estudios Riojanos (convocatoria de 2017).
\end{abstract}

Fecha de recepción: 22 de diciembre de 2017

Fecha de aceptación: 28 de junio de 2018 
his production, he writes following a classic literary canon in terms of contents and structure and he shapes his poetic works with criteria far from current trends. He believes that the result will surpass even the compositions of the already consecrated authors of the Spanish Golden Age. He materialises one of his most risky bets in the fourth book of the second part of Las Eróticas o amatorias, a work published in 1618.

In the following article the literary life of the author is contextualised, his poetic works are described grosso modo and several compositions of his book Las latinas are commented on from the point of view of content and metrics. The aim is to shed light on the knowledge of an author who, although he does not eclipse the authors who structure Spanish literature in the Golden Age, despite trying from the very cover of his work, adopts correct decisions on metric issues in a moment of settlement of compositional criteria in verse.

Keywords: Classic tradition, Esteban Manuel de Villegas, Spanish Golden Age, meter.

\section{Esteban Manuel de Villegas. Vida literaria}

El mundo literario del Siglo de Oro español se caracterizó por la convivencia de importantes autores de primera fila con multitud de autores de segundas, terceras y cuartas filas. Estos conformaron la base sobre la que se sustentaron y destacaron las figuras señeras de Quevedo, Lope, Góngora, Calderón o Miguel de Cervantes.

Como nombre imprescindible en ese panorama sobresale la figura de Esteban Manuel de Villegas ${ }^{2}$. Este autor fue bautizado el 5 de enero de 1589 en Matute. Allí se había establecido su padre, Francisco de Villegas (descendiente de menor rango de la nobleza montañesa santanderina) tras casarse con Francisca González, natural del vecino pueblo de Pedroso, con la que tuvo ocho hijos. Tras la muerte de Francisco de Villegas, en 1592, Francisca traslada la residencia familiar a Nájera, donde crecería definitivamente el pequeño Esteban y de donde saldría para formarse académicamente a Madrid y Salamanca entre 1600 y 1613. En aquellos bulliciosos núcleos de vida

2 Se recoge en este apartado un resumen de la vida de Esteban Manuel de Villegas, para que el lector sitúe al autor que nos ocupa. Los primeros datos biográficos aparecen recogidos por De los Ríos (1774) en la edición que hace de la obra poética del autor. Menéndez Pelayo (1953), a la hora de escribir la biografía de Villegas, se limita a resumir los datos que proporciona Vicente de los Ríos. Ya en el siglo xx son autores, sobre todo locales, los que matizan y amplían esos datos: Hernáez Tobías (1949) interpreta los datos de las partidas de nacimiento y matrimonio del autor, así como otros datos extraídos de documentos públicos como demandas y resoluciones judiciales; Cillero Ulecia (1971) repasa la vida del afincado en Nájera; Del Campo (1972) escribe la primera obra que, con carácter divulgativo, hace un repaso pormenorizado por la vida y obras de Villegas; y ya por fin, Bravo Vega (1989) publica un volumen en el que describe e interpreta los sucesos de la vida de nuestro autor. A partir de ahí los diversos estudiosos que han tratado la figura del autor riojano han reescrito los datos que de las fuentes anteriores manaban: Emilio Magaña Orúe, José Luis Pérez Pastor, M. ${ }^{\mathrm{a}}$ Ángeles Díez Coronado, Jorge Fernández López, Jorge Sáenz Herrero, Eva Marqués López... 
cortesana y de saber universitario, además de adquirir una sólida formación en las lenguas y literaturas griega y latina, el poeta quedó prendado de la actividad cultural y literaria que siempre añoró a su vuelta a Nájera, lugar en el que la gestión de los intereses económicos familiares reclamó su presencia a partir de la segunda década del siglo Xvir.

Ya en su estancia en Madrid, Esteban Manuel de Villegas había sido acusado de presuntuoso con cierta sorna por parte de escritores de la talla de Cervantes. Esta actitud tendría su continuación cuando en 1618 Esteban Manuel de Villegas publicó su obra poética principal, titulada Las Eróticas o Amatorias. En la portada, un grabado reafirmaba el carácter arrogante de nuestro autor. Contenía el escudo de armas de Felipe III flanqueado por dos figuras humanas que mostraban sobre sus cabezas los nombres de Anacreonte y Horacio, respectivamente. Debajo del escudo se podía leer el título, el autor y la dedicatoria. Completaba la página un emblema bajo los pedestales que representaba veinticuatro estrellas sobre un sol naciente en medio del mar, encima de sus rayos se leía: Me surgente, quid istae? ('Cuando yo salgo ¿qué son esas a mi lado?’). Subrayaba el conjunto la inscripción: Sicut sol matutinus ('Como el sol matutino'). El mundillo literario comprendió sin gran esfuerzo que el sol representaba al joven Villegas y que las veinticuatro estrellas eran sus compañeros de profesión, cuyas obras palidecían ante la luz del astro rey, calificado, además de «matutino», en un juego de palabras alusivo a su Matute natal. El revuelo ocasionado provocó la retirada del grabado en una segunda impresión del libro, que tendría lugar en 1620.

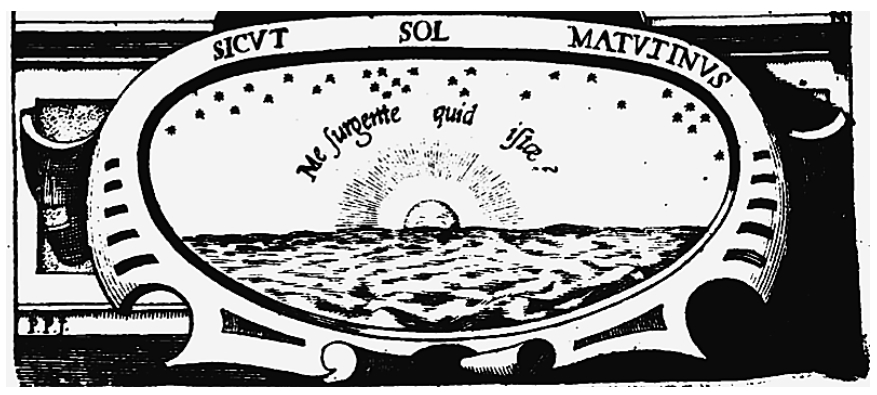

Grabado que aparecía en la $1 .^{\text {a }}$ portada de 1618.

Más allá de la provocación de la portada, Las Eróticas fue una obra de calado con una estructura cuidadosamente planificada en la que destaca la capacidad del poeta tanto en la imitación de los esquemas clásicos en lengua castellana, como en la experimentación en la adaptación de los mismos en el marco de la métrica española, siempre desde una postura marcadamente clasicista. 
Aparte de Las Eróticas, la labor poética de Villegas se completa con una composición denominada Antiteatro, así como con un libro de sátiras, hoy perdido. Su labor humanística, por otro lado, la desarrolla con las denominadas Dissertationes Criticae y una traducción de La consolación de la filosofía de Boecio. La primera fue su obra cumbre en el campo de la composición teórico-interpretativa. Se trata de una obra de madurez, en la que comenzó a trabajar alrededor de 1631. Las Dissertationes son una colección de 231 textos en latín en los que aborda multitud de aspectos relacionados con pasajes de autores clásicos, sobre todo en lo tocante al ámbito de la crítica textual. De forma filológica y personal a la vez, Villegas propone numerosas alternativas a determinados lugares de las obras de Ausonio, Séneca el viejo, Quinto Aurelio Símaco, Marciano Capela, Varrón, Catulo y Horacio, entre otros. Al hilo del tratamiento de dichas cuestiones textuales, como es de esperar, surgen muchas otras consideraciones (léxicas, históricas, métricas, etimológicas...) en las que Villegas aprovecha para desplegar una considerable erudición. Pese a ello, la obra no se llevó a la imprenta y permanece inédita.

A los diversos pleitos por la hacienda que ocuparon su vida, y que le granjearon fama de litigante entre la crítica, se añadió en 1644 un largo proceso inquisitorial ${ }^{3}$ que duraría hasta 1660: nuestro Villegas había defendido en público una serie de opiniones acerca del libre albedrío que, si bien razonables y coherentes a la luz de un humanismo erasmista, resultaban imprudentes en la España del momento. Sufrió once meses prisión en Logroño, un breve destierro de tres meses en Santa María de Ribarredonda (Burgos) y la expurgación de su biblioteca, en la que fue requisado su Libro de Sátiras. Por su avanzada edad (70 años) se le permitió volver a Nájera en el mencionado año de 1660.

De regreso a su casa, reanudó su actividad intelectual y en 1665 publicó la mencionada traducción de Boecio (a excepción de la parte dedicada al libre albedrío, que permanece en latín para evitar problemas mayores con el Santo Oficio), pero no su Antiteatro, a pesar de que la licencia de impresión incluía las dos obras.

Esteban Manuel de Villegas pasó los últimos años de su vida en medio de múltiples estrecheces económicas derivadas de los continuos pleitos, destinados al cobro de los juros, rentas y herencias de los que se nutrían las arcas familiares, a los que se sumaron los costes producidos por el sobredicho proceso inquisitorial. Cumplidos los ochenta años, murió el 3 de septiembre de 1669.

3 Léase a este respecto, además de los estudios biográficos señalados, Cánovas del Castillo (1882) y Gil (1997: 431-436). 
La actividad creativa y humanística de Villegas mereció en vida la atención de alguno de sus contemporáneos más ilustres. Así, Lope de Vega en su Laurel de Apolo (1629) dedicó unos versos de halago a su memoria. En ellos elogiaba tanto su faceta de poeta, como su actividad erudita, sin dejar de lado una irónica alusión a la arrogancia que le llevó a publicar el mencionado emblema del sol en la portada de Las Eróticas:

Aspire luego de Pegaso al monte

el dulce traductor de Anacreonte,

cuyos estudios con perpetua gloria

libraran del olvido su memoria,

aunque dijo que todos se escondiesen

cuando los rayos de su ingenio viesen.

La posteridad, sin embargo, acabó dedicando una desigual atención a su obra. Su consagración literaria no llegó hasta el siglo XviII, cuando sus ideales clasicistas encontraron eco en la estética general del periodo, sobre todo en lo tocante a sus composiciones de corte anacreóntico. Es también en este siglo XVIII, en 1774 concretamente, como consecuencia de esa coincidencia estética, cuando Vicente de los Ríos realizó la edición de la obra poética de Villegas, incluyendo la traducción de la Consolación. En la misma época, López de Sedano había ido publicando parcialmente Las Eróticas en su Parnaso Español, concretamente en los volúmenes aparecidos entre 1768 y 1774. Desde entonces la imagen de Villegas ha seguido siendo parcial y esto a pesar de que Las Eróticas tuvieran un modesto lugar en la colección «Clásicos castellanos», en la que desde 1913 y en las sucesivas reediciones la obra quedaba prácticamente reducida a la primera parte. Desde los años ochenta se viene acometiendo la labor de estudiar, divulgar y editar la obra de este humanista de forma completa y con las más apropiadas garantías filológicas. Eva Marqués López, Jorge Fernández López, Emilio Magaña Orúe, M. ángeles Díez Coronado y José Luis Pérez Pastor han dedicado a este ámbito diversos proyectos de investigación, lo que ha conducido, a su vez, a la edición y comentario de las partes bucólica y elegíaca del conjunto de Las Eróticas, hoy disponibles para su lectura junto con una antología de Las Eróticas.

\section{LAS ERÓTICAS O AMATORIAS}

Las Eróticas aparecieron publicadas en Nájera, en el año 1618, de la mano de Juan de Mongastón. Como señala Bravo Vega (1989: 89-104), y hemos constatado con la revisión de las ediciones, solo hubo una edición de esta obra, la de 1618, de la que se realizaron tres impresiones, las cuales presentan ligerísimas discrepancias reducidas a unas pocas erratas que las diferencian entre sí. Fue la introducción de una nueva portada en 1620, que con- 
signaba dicho año, y el hecho de que en la portada interior de la segunda parte figure el año de 1617, lo que hizo que diversos estudiosos pensaran en la existencia de varias ediciones, que llegarían hasta cinco.

La obra consta de dos partes, y cada una de estas de cuatro libros en los que el autor tiene como referentes constantes poemas de la Antigüedad clásica que recrea, reelabora o versiona en diferentes grados de cercanía con los originales ${ }^{4}$. Es en la primera parte de la obra donde mejor podemos observar la utilización de los géneros clásicos en el riojano, basada en una estructura simétrica que dedica dos libros a Horacio (Odas y Versiones) y otros dos a Anacreonte (Delicias y Anacreonte) y en dos momentos diferentes del proceso literario (creación y traducción). La segunda parte de Las Eróticas también está formada por cuatro libros. Las simetrías que podíamos observar en la primera parte de la obra no están tan bien definidas aquí, y la extensión de los libros es menor. Los dos primeros responden al clasicismo del que hizo gala Villegas anteriormente: el riojano eligió el título Elegías para designar con él un conjunto de catorce epístolas y sátiras que constituyen el libro primero de la segunda parte, mientras que reservó la denominación de Idilios para las cuatro composiciones bucólicas que conforman el libro segundo de esta segunda parte; el tercero y cuarto, titulados respectivamente Sonetos y Epigramas (doce sonetos y nueve epigramas) y Las latinas (una égloga, dos poemas en estrofas sáficas y otros dos en dísticos), nos transportan a la actividad literaria de la época.

\section{LAS LATINAS: ESTRUCTURA Y CONTENIDO DE UN LIBRO DE TRADICIÓN CLÁSICA}

El libro cuarto de la obra de Villegas está compuesto por cinco poemas que representan el último estadio de la labor poética de nuestro autor. Ya ha traducido a los clásicos, los ha versionado y ahora compone «a la manera de». Las Latinas o Poesías Castellanas en Metro Latino lo forman cinco poemas de inspiración clásica tanto por su temática como por su metro.

La primera composición es una égloga en hexámetros, las dos siguientes llevan el título genérico de «Sáficos» y las dos últimas de «Dísticos». Desde el punto de vista del contenido, en la primera se hace patente el Virgilio bucólico. Los nombres de los protagonistas, el oficio, el lugar de encuentro, los sucesos... recuerdan la Arcadia: «Lícidas y Coridón, pastores ambos...», verso 1 . Los dos poemas siguientes temáticamente vienen a parar en el rechazo por parte de una fría amante, aunque aquí el contexto en que se sitúa a los

4 Sobre esta faceta de traductor/adaptador de Villegas, cf. Menéndez Pelayo (1953), García Calvo (1950), Bocchetta (1970), De Colombi Monguió (1982), Bravo Vega (1989). Sobre sus dotes de helenista, De Andrés (1988: 228-231, 233-236), Marina Sáez (2001-2002). Por su interés por Marcial, Marina Sáez (2002) y Fernández López y Sáenz Herrero (2008). 
protagonistas es la ribera del río Najerilla que discurre por la ciudad donde se crió nuestro autor. Las dos últimas, los dísticos, tratan de reproducir la frescura de los versos clásicos del mismo nombre con un contenido mitológico.

La égloga se divide en tres partes; en la primera se presentan los protagonistas (dos pastores) y el autor aprovecha la figura de uno de ellos para introducir y desarrollar una amplia dedicatoria a Don Francisco de Castro, uno de los nobles a quien trata de complacer Villegas en pos de apoyo ${ }^{5}$. Sigue un diálogo entre los pastores, que desemboca en un canto amebeo recitado por ellos en tiradas de cinco versos cada uno. Los dos pastores, de nombre Lícidas y Coridón, son dos muchachos jóvenes que a la sombra de un arbusto se lamentan. Villegas enlaza en esta primera parte la dedicatoria con la que trata de justificar su dedicación a un género menor, como es la poesía bucólica, a la par que asegura que la aparición del duque de Castro en esta singular poesía le reportará fama eterna. Sigue, en la segunda parte, la contextualización física del lugar y anímica de los pastores, que da pie a la tercera parte del poema que es el canto amebeo. Entonces cada pastor recita cinco versos, de los cuales, el primero es común siempre y el tema es el del rechazo amoroso por parte de una joven bella, pero fría y distante que acaba sucumbiendo y provocando la explosión de la naturaleza.

Los dos poemas denominados «Saphicos»y «Más saphicos», que siguen a la égloga, repiten la temática del amor, aunque desde otra perspectiva. Ya no hay diálogo en el que los protagonistas intercambien opiniones; ahora nos encontramos con un monólogo lastimero y ante un diálogo en el que el interlocutor solo da pie al desarrollo de las ideas del protagonista de la composición.

Los dísticos siguen la línea descrita hasta ahora, pero con mayor brevedad, los dos poemas suman un total de seis versos (4 y 2). Son poemas en los que el amor es protagonista, aunque de manera indirecta. En el primero a través de una conversación entre Diana, diosa de la caza, y Venus, diosa del amor; y en el segundo rememorando el hecho que provocó la Guerra de Troya, el rapto de Helena por parte del enamorado Paris, lo cual llevó a la muerte a muchos griegos.

No resultan, en consecuencia, estas composiciones excesivamente originales en cuanto a la temática, aunque sí es cierto que Villegas reinterpreta el material clásico dándole actualidad con la introducción de un marco geográfico local («Saphicos»), o con la dedicatoria dirigida a un noble del momento («Égloga en hexámetros»), por ejemplo.

5 En el quinto apartado de este trabajo se recogen las composiciones que se comentan, con la idea de que el lector constate lo que se va explicando. 
Sí son más interesantes en estos poemas las cuestiones métricas, ya que suponen un intento serio de adaptación de metros grecorromanos a la poesía española del Siglo de Oro. Adaptación que, para cuando comienza a componer Villegas, ya cuenta con una base teórica que emanaba de las preceptivas que venían publicándose desde 1492: Antonio de Nebrija dedica en su Gramática castellana un capítulo, titulado «Rhytmica», a adaptar la métrica latina a los versos castellanos, sustituyendo la cantidad silábica por el acento como generador del ritmo. Esta misma idea es la que leemos en otros preceptistas áureos como Pinciano o Rengifo, aunque ellos toman como base la métrica italiana ${ }^{6}$.

En los siglos precedentes el octosílabo como verso de arte menor y el alejandrino como el rey del arte mayor lo habían significado todo para la composición en verso; pero ya a mediados del siglo XVI el primero saturaba y el segundo resultaba pesado. Si a esto unimos el hecho de que el Renacimiento había permitido el conocimiento total de Horacio, de sus poemas y obras doctrinales, tendremos todos los ingredientes para los experimentos métricos que ejecutan autores como nuestro Villegas.

Villegas conocía y había estudiado la obra de Nebrija y había leído también a López Pinciano (1596), quien defendía que, teniendo en cuenta el número de sílabas de los versos y dónde va situado el acento, se podrían escribir versos castellanos con la misma cadencia que tenían los clásicos. El problema, que probablemente no ignoraba el de Matute, es que los pies sustituibles no tienen un lugar fijo para los acentos y que por tanto las posibilidades eran casi infinitas. A pesar de ello compone la primera poesía del libro cuarto, hilvanando 94 hexámetros en una égloga a la manera virgiliana. Desde el punto de vista métrico nos encontramos con versos de 14 a 17 sílabas que repiten en términos acentuales la combinación dáctilo-espondeo propia del final de los hexámetros, consiguiendo así cierta similitud rítmica con el original, aunque carecen de la variedad del texto latino:

Lícidas y Coridón, Coridón el amante de Filis, pastor el uno de cabras, el otro de blancas ovejas, ambos a dos tiernos, mozos ambos, árcades ambos, viendo que los rayos del sol fatigaban el orbe

5 y que vibrando fuego feroz la canícula ladra, al puro cristal, que cría la fuente sonora, llevados del son alegre de su blando susurro, las plantas veloces mueven, los pasos animan $\mathrm{y}$ al tronco de un verde enebro se sientan amigos.

6 Clásico, pero imperecedero, resulta para desarrollar estos aspectos Díez Echarri (1970) y para aspectos concretos de la labor de Villegas también se puede consultar García Calvo (2006). 
Más acertado anduvo el riojano, según la crítica $^{7}$, en la adaptación del sáfico latino a la manera de la estrofa sáfico-adónica de Horacio. Según las preceptivas áureas en lo que a la versificación silábico-acentual se refiere, un sáfico es un endecasílabo dividido en dos hemistiquios de cinco y seis sílabas respectivamente con acentuación obligada en la cuarta y octava sílabas. La métrica latina es más flexible, pues solo tiene como obligatoria una cesura pentemímera y la acentuación en la cuarta sílaba.

Villegas, siguiendo la preceptiva castellana, escribe versos sáficos de 11 sílabas en estrofas de cuatro versos que se cierran con un adonio pentasilábico. Todos ellos van acentuados en cuarta y octava sílaba y los adonios simulan el final de un hexámetro en lo que hace a la acentuación (llevan acento en la primera y cuarta):

Ya por el cierzo, boreal Pegaso, dime, de dónde sacudiendo vienes tantos olores de valor Sabeo, dulce paloma?

$5 \quad$ Entre tus plumas de color nevado pálidas miro del amor violas, y entre tus uñas de granate llevas rosas y flores.

Este esquema, parcialmente clásico, es el que se considerará el único a partir de Villegas. Sus sucesores lo repetirán sin cuestionarse ni un acento. De ahí que durante un par de siglos se tuviera a Villegas como el introductor del verso en España, a pesar de que, como quedó demostrado por Menéndez Pelayo, según explica Eladio del Campo (1972), lo utilizaron antes, entre otros, Sánchez de las Brozas.

El último intento de adaptación métrica en este cuarto libro se reduce a seis versos que, agrupados en cuatro y dos, dan forma a dos poemas escritos en dísticos, suma de heptasílabo y pentasílabo o viceversa. Los problemas de adaptación con que se encuentra aquí Villegas son los mismos que observábamos con el hexámetro, el otro verso del ritmo dactílico. Opta por reproducir un esquema fijo, quince sílabas para los hexámetros con un final de dáctilo-espondeo, y trece para los pentasílabos con final espondeo-espondeo:

Como el monte sigues a Diana, dijo Cytheres, Dictyna hermosa, siendo caza fea.

No me la desprecies Cyprida, responde Diana, tu también fuiste caza, la red lo diga.

7 Léanse los comentarios de las adaptaciones hechas por Villegas en las obras citadas de García Calvo y Díez Echarri. 


\section{Conclusión}

En suma, Esteban Manuel de Villegas fue un autor del Barroco español, anclado en un clasicismo incomprendido por el público de su época, que dio a la luz una obra poética de gran valor para la pervivencia del mundo literario clásico por cuestiones de contenido y estructura. Hizo visibles a través de traducciones, recreaciones e imitaciones (como es el caso del libro que nos ha ocupado) a autores grecolatinos de la talla de Anacreonte, Horacio, Catulo, Virgilio o Marcial y contribuyó al desarrollo de la métrica española con aportaciones propias puestas en práctica, que derivaban de su amplio conocimiento de la métrica clásica.

\section{Textos}

\section{1. Égloga en hexámetros}

Lícidas — Coridón - Poeta

Poeta

Lícidas y Coridón, Coridón el amante de Filis, pastor el uno de cabras, el otro de blancas ovejas, ambos a dos tiernos, mozos ambos, árcades ambos, viendo que los rayos del sol fatigaban el orbe

5 y que vibrando fuego feroz la canícula ladra, al puro cristal, que cría la fuente sonora, llevados del son alegre de su blando susurro, las plantas veloces mueven, los pasos animan $\mathrm{y}$ al tronco de un verde enebro se sientan amigos.

10 Tú, que los erguidos sobrepujas del hondo Timavo peñones, generoso Duque, con tu ínclita frente, si acaso tocare el eco de mi rústica avena tus sienes, si acaso llega a tu fértil abono, Francisco, del acento mío la sonora Talía,

15 oye pío, responde grato, censura severo. No menos al caro hermano generoso retratas, que al tronco prudente sigues, generoso naciste héroe, que guarde el cielo dilatando tus años. Lícidas y Coridón, Coridón el amante de Filis,

20 pastores, las Musas aman, recrearte desean. Tú, cuerdo, perdona en tanto la bárbara Musa que presto, inspirando Peán con amigo coturno, en trompa, que al Olimpo llegue por el ábrego suelta, tu fama llevarán los ecos del Ganges al Istro,

25 y luego, torciendo el vuelo, del Aquilo al Austro. Febo la cumbre seca, que su luz a la sombra recoge, 
Procne lamenta grave, Venus arde, la fuente susurra, el fresco arroyuelo ríe, y el aire se crespa.

Lícidas entonces: "Coridón discreto", le dice, «en tanto que el viento fresco se mueve ligero, bullendo las blancas aguas, regalando las hojas, suena, zagalejo, y al son de tu cítara canta.» « Oh, cuán agradable, oh, cuán dulce al árcade suelo, cuán pío», responde Coridón, «al céfiro blando el tuyo será sin duda, si, Lícidas, cantas!»

LÍCIDAS

No burles, Coridón; Coridón, no burles, amigo; usa de lenguajes píos y el irónico deja.

CORIDón

No burlo, verdades hablo, verdades abono;

Lícidas, ingrato pagas al amor que te muestro, viendo que, si pago, debo más a tu dulce lisonja. Mas ya que el señor de Delo nos iguala su curso, mediando con luz hermosa la cuarta morada, ea, dale al viento, dale ya la bucólica Musa, y en premio del canto pío, de mi parda manada escoge un cabrito luego de presta viveza, ya tierno, ya grande sea, y a tu blanca le junta.

\section{LÍ́CIDAS}

No el premio, Coridón, solo tu consejo recibo; por tanto, prevente ahora, y a mi cítara sigue.

CORIDón

Suena la dulce chelys, dame pie, que tu cítara sigo.

\section{LÍCIDAS}

50 Mueve, sonora Clío, dale voz a mi rústica Musa.

Páramos de Arcadia, que miráis de mi dulce Licoris los ojos, la blanca mano, la frente serena, con ramas, con verdes hojas, con amable susurro al viento, que os brinda pío, celebradla suaves.

\section{CORIDÓN}

55 Mueve, sonora Clío, dale voz a mi rústica Musa. Praderas del verde suelo que el Ménalo cría, Filis os ha pisado; mirad que mi Filis amena al Mayo produce flores; si os obliga su planta, al viento, que os brinda pío, celebradla suaves.

\section{LÍCIDAS}

60 Mueve, sonora Clío, dale voz a mi rústica Musa.

Si Mopso templó las iras de su dura Fenisa 
y menos tibio llenó de requiebros el aire, ¿qué, ingrata pastora, temes? ¡qué recelas, amante, en tanto que a Mopso miras y a Fenisa casados?

CORIDÓN

65 Mueve, sonora Clío, dale voz a mi rústica Musa.

Dichoso por cierto miras tu cónyuge, Mopso; ingrata mostró su hielo, mas fuete mudable. ¡Oh, quién Mopso fuera, si Mopso a Filis amara! Mas, Coridón, ¿qué temes, Coridón, si ya quiere Fenisa?

\section{LÍCIDAS}

70 Mueve, sonora Clío, dale voz a mi rústica Musa.

Ya las avecillas tímidas lograrán su manida sin riesgo del grave daño del sacre pirata; no se promete menos de tu boda, rebelde Fenisa; gózala mil años, y tá Mopso, otro tanto la goza.

\section{CORIDÓN}

75 Mueve, sonora Clío, dale voz a mi rústica Musa.

Mil años, pastora, vivas; mil años a Mopso goces, amando pía, ya que Mopso es amante suave;

y tú, dichoso vaquero, a los hados amigo, libre de sospechas goces a tu dulce Fenisa.

\section{LÍCIDAS}

80 Mueve, sonora Clío, dale voz a mi rústica Musa. Seis veces el verde soto coronó su cabeza de nardo, de amarillo trébol, de morada víola, en tanto que el pecho frío de mi casta Licoris al rayo del ruego mío deshizo su hielo.

\section{CORIDÓN}

85 Mueve, sonora Clío, dale voz a mi rústica Musa. Seis veces la florida Venus con afeite de nácar discreta sazonó la rosa, y discreta mi Filis, seis veces oyó mi chelys, seis veces, y dijo: «Venciste, Coridón; tu voz de sirena me vence.»

\section{LÍCIDAS}

90 Mueve, sonora Clío, dale voz a mi rústica Musa.

Mas cese la dulce chelys; los brazos apresta, los brazos te pido, Coridón, los brazos, amigo; goce de tus brazos, pues yo de tu másica gozo, y en tanto, paced vosotras, paced, mis ovejas. 


\subsection{Saphicos}

1 Dulce vecino de la verde selva huésped eterno del Abril florido, vital aliento de la madre Venus, Zephyro blando.

$5 \quad$ Si de mis ansias el amor supiste, tú, que las quejas de mi voz llevaste, oye, no temas, y a mi nympha dile, dile que muero.

9 Phylis un tiempo mi dolor sabía, Phylis un tiempo mi dolor lloraba, quísome un tiempo, mas ahora temo, temo sus iras.

13 Así los dioses con amor paterno, así los cielos con amor benigno nieguen al tiempo que feliz volares nieve a la tierra.

17 Jamás el peso de la nube parda, cuando amenace la elevada cumbre, toque tus hombros, ni su mal granizo hiera tus alas.

\subsection{Distichos}

Como el monte sigues a Diana, dijo Cytheres, Dictyna hermosa, siendo caza fea?

No me la desprecies Cyprida, responde Diana, tu también fuiste caza, la red lo diga.

\section{Bibliografía}

Bocchetta, V. (1970): Horacio en Villegas y en Fray Luis de León. Madrid, Gredos.

Bravo Vega, J. (1989): Esteban Manuel de Villegas (1589-1669). Estudio biográfico. Logroño, Consejería de Educación, Cultura y Deportes de La Rioja.

Cánovas del Castillo, A. (1882): Noticias y documentos inéditos acerca del proceso inquisitorial formado a Don Esteban Manuel de Villegas. Madrid, M.G. Hernández.

Cillero Ulecia, A. (1971): El cisne del Najerilla (Don Esteban Manuel de Villegas). Logroño, Editorial Ochoa.

De Andrés, E. (1988): Helenistas españoles del siglo XVII. Madrid, Fundación Universitaria Española.

De Colombi Monguió, A. (1982): «La Oda xir de Esteban Manuel de Villegas y su tradición poética». Modern Language Studies, 12, págs. 31-40.

De Los Ríos, V. (1774): «Memorias de la vida de D. Esteban Manuel de Villegas». En Esteban M. de Villegas, Las eróticas o amatorias. Madrid, Antonio de Sancha, págs. 3-39. 
Del Campo Íñiguez, E. (1972): D. Esteban Manuel de Villegas: algunos aspectos de su vida y obra. Logroño, Instituto de Estudios Riojanos.

Díez Echarri, E. (1970): Teorías métricas del siglo de oro. Madrid, csic.

Fernández López, J. y SÁenz Herrero, J. (2008): «La retórica del epigrama de Esteban Manuel de Villegas». Berceo, 155, págs. 55-76.

García Calvo, A. (1950): «Unas notas sobre adaptación de metros clásicos por don Esteban de Villegas». Boletín de la Biblioteca Menéndez Pelayo, 1, págs. 92-105.

- (2006): Tratado de rítmica y prosodia y de métrica y versificación. Madrid, Editorial Lucina.

Gil, L. (1997²): Panorama social del Humanismo Español. Madrid, Tecnos.

Hernáez Tobías, L. (1949): «Algunos datos nuevos para la biografía de D. Esteban de Villegas», Berceo 12, págs. 441-444.

López Pinciano, A. (1596): Philosophía antigua poética. Madrid [ed. y pról. J. Rico Verdú. Madrid, Fundación José Antonio de Castro, 1998].

Marina SÁez, R.M. (2002): "Las traducciones de Marcial de Bartolomé Leonardo de Argensola». En Maestre Maestre, J.M. et al. (eds.): Humanismo y pervivencia del mundo clásico. Homenaje a Antonio Fontán, vol. IV. Madrid-Alcañiz-Cádiz, Instituto de Estudios Humanísticos-CSIC-Laberinto, págs. 1711-1722.

- (2001-2002): «La traducción de Villegas de la Oda I 35 de Horacio y su relación con la versión de Bartolomé Leonardo de Argensola». Cuadernos de Investigación Filológica, 27-28, págs. 323-338.

Menéndez Pelayo, M. (1953): «Villegas, Esteban M. de». En Biblioteca de traductores españoles, vol. IV. Santander, CSIC, págs. 362-381. 